\title{
1.3 Structural components of the process of forming the spiritual values of student youth
}

In modern conditions, the student is the main subject of the reform and innovative development of higher education and society, which is why the issue of the formation of spiritual values in student youth is becoming important.

At the same time, the analysis of pedagogical theory and educational practice demonstrates the disadvantages of the preparation of high school teachers for the implementation of the relevant educational activities, the inadequate level of orientation of educational programs and the involvement of public organizations in solving this problem is observed. Therefore, personally oriented educational influences should be directed to the process of formation of spiritual values, where the student is a priority.

The purpose of the article is seen in the definition of the structural components of the spiritual values of the personality, psychological mechanisms and pedagogical background of their formation during the period of study in a higher education institution.

We define the concept of "spiritual values of student youth" as an integral personal formation aimed at other people (responsibility, tolerance, mercy) and on myself (dignity, self-sufficiency), which makes constructive behavior and ensures the possibility of realizing the subject-subject interaction, adaptation and self-realization of the personality in society.

The analysis of the scientific makes it possible to conclude that the student's age is optimal for the development of value-semantic structures of consciousness of the personality and is characterized as the final stage of preparation for entry into independent professional activity. At this age, moral instincts will manifest themselves in the future as value orientations in the practice and behavior of the personality. It is at this age that the role of persuasion and responsibility for one or the other life choices and for values grows, such qualities as ambitiousness, determination, perseverance, independence, initiative, ability to manage yourself are strengthened, and the interest in spiritual and moral problems is increased. 
Formation of spiritual values in students requires consideration of their structural components - it is a question of the content structure of this integral entity. It can be represented by interconnected and interdependent components: cognitive, emotional and value-based, and praxical.

The definition of structural components is conditioned by the conceptual provisions on the dialectical unity of the intellectual and emotional factors of consciousness. After all, without knowledge of spiritual values it is impossible to form a relation to them. At the same time, without emotional perception, positive attitude and interest in spiritual values, difficulties will arise in mastering knowledge. This explains the isolation of the cognitive component, which determines the capture of beliefs and knowledge about the phenomenon.

The acquired beliefs and knowledge provide the opportunity to form a person's attitude towards the subject of knowledge. An emotional (positive or negative) adjustment is formed, subjective evaluation criteria that will determine susceptibility to the formation of spiritual values are formed. So, the emotional and value-based component implies a positive attitude to the content and manifestations of spiritual values.

The acquired knowledge and positive attitude are reflected in practice. Therefore, the ability to realize spiritual values in everyday life and professional activities determines the emphasizing of the praxical component. At the same time, it should be borne in mind that spiritual values are accumulated in such qualities of personality as: responsibility, mercy, tolerance, dignity, self-sufficiency. The appropriation of such values by young boys and girls ensures the effectiveness of interaction, communication with peers, relatives and acquaintances, their successful self-realization and adaptation in society.

The emotional and value-based component of the students' spiritual values is manifested through the value attitude of young boys and girls to themselves, others, surrounding reality and is a benchmark in their spiritual growth. It also implies a humanistic interaction adjustment; detection of tolerance, mercy, responsibility; developed empathy; positive "I-concept"; emotional self-regulation. 
Formation of spiritual values in students is impossible without emotional experiences, because they are developing a value relation to this phenomenon. This is due to the fact that at the young age a significant experience of emotional life is already acquired. Student youth not only can manage its emotions, give a moral assessment of aspirations, but also deliberately tries to educate itself in high moral feelings. Selfesteem of actions and feelings, aspiration for a moral ideal - all this develops and deepens the most important of moral feelings - a sense of duty, produces the ability to give a moral assessment - conscience.

Spiritual values are semantic entities directed at other people and itself. That is why they are always connected with the emotional contact between the two subjects. Properly reflecting the feelings of another person, we signal how we understand its internal state. Productivity of interaction and understanding depends in such cases not so much on actual information, but from sets, feelings, emotional manifestations.

Given this, the ability to respond emotionally to the experiences of others, to show mercy, tolerance, the ability to use emotional expression as a means of communication, to express emotions purposefully, to control their manifestation arbitrarily, the ability to adequately perceive, evaluate and understand their own emotions and emotions of other people, be aware of, reflect emotional states, control emotions, etc., is very important in the process of interaction.

Due to the growth in the student's age of self-control and self-criticism of their behavior, forms of manifestation of feelings change. Changes and new formations in feelings are evidence of the maturity of young people, their spiritual growth. They are a manifestation of the formation of their consciousness and self-consciousness, their interests, in particular the interest in themselves, other people, in their own and others' experiences. Student youth has the ability to empathize, understand and respond to the experiences of another person. It is worth noting that the feeling of personality is not simply experienced by it, but expresses its subjective attitude to certain phenomena of reality, persons, they become the motives of its actions.

Spiritual values are considered, first of all, as the personal formation of the student, which is reflected in its beliefs, views, needs, motives, feelings, and 
interactions. They are a tool for self-realization of a student in a relationship with other people. Important in the development of the emotional and value-based component is the awareness of young people of their own abilities, needs, motives of behavior, valuebased orientations.

The aspiration for self-determination, self-affirmation, self-realization belongs to one of the most important needs of students and is a condition for their harmonious spiritual development. The notion of itself, its "I" inevitably gives rise to the need to realize its capabilities and abilities.

The emotional and value-based component of spiritual values is a complex of motives that motivate young people to interact, establish an active life position, selfunderstand, self-improve. First of all, external motives of spiritual values include social motives widely represented (desire to occupy a certain place in society, increase social status, motives of personal self-realization and prestige) and narrowly represented (desire to have a certain status in a particular social group). The internal ones include cognitive motives, self-affirmation, identification with another person, selfdevelopment and self-actualization (this refers to the desire for self-improvement, the desire to increase its individual capabilities, to realize individual potential), affiliation (the desire to establish relationships with other people), personal growth (the ability to have self control in any situation).

Formation of spiritual values of students is conditioned by a complicated hierarchical system of socially meaningful and personal motives; in it the higher level of motivation is the transformation of the need into conscious interest, personal value, and the value - into the purpose of the activity. The development of the motives of spiritual values is carried out in the direction from external impulses to the appearance of their own motivational entities. But the formation of the spiritual values of students should be spoken only when in the process of interaction or communication another person acts for them as an object of value attitude, manifested in recognition of its needs, interests; orientation towards positive in a person.

An important condition for the successful formation of students' spiritual values is identification, empathy. In the process of identification, there primarily takes place 
interpersonal regulation of the behavior of boys and girls, assimilation, identification of partners in communication and, as a consequence, - mutual understanding. The phenomenon of identification belongs to the most significant and most vivid processes of human communication. In particular, M. Herbert considers identification as a process by which one subject is likened to another, accepting its values, views, sets, life experiences, as well as specific forms of its behavior.

One of the mechanisms that mediates the formation of spiritual values for students is empathy. In the aspect of interpersonal interaction or communication, the empathy is regarded by scientists as fulfilled for another person introspection or the ability to feel, see, distinguish, reproduce and respond to feelings and experiences of other people. It has a complex structure, including cognitive, emotional and behavioral components. As a cognitive phenomenon, empathy is a way of understanding another person, aimed at analyzing its personality, and not only meaningful, but also intuitive knowledge of its emotional experiences. It is the ability to penetrate the affective orientation of another person, it is a sympathy for its experiences, the ability to be attached to the emotional life of another person, to share its emotional states, to experience emotional well-being or trouble. And, finally, the behavioral component manifests itself in the ability to "put" yourself into another person and influence the changes in its personality, its support and active assistance.

So, we see empathy as an important factor in the student's spiritual development. It is an effective means of disclosure, assimilation and balance of the internal content of interpersonal relationships and social norms. Without it, adequate understanding is hardly possible. The manifestation of empathy in the communication process indicates the general set not only for understanding the formal part of communication, but for entering its hidden meaning, the state of another person that appears primarily by nonverbal means - intonation, gestures, postures. That is there is a direct correlation: the higher is the overall culture of the personality, the more intense is the ability to empathize, sympathize with people. The egocentric emotions here are replaced by altruistic motives. Acting complicity in the fate of another person, compassion for another's grief enrich and develop interpersonal relationships. Actualization of 
empathic processes (development of emotional susceptibility, feeling of internal promotion to another person) is realized in the process of interaction, communication of senior pupils, the meaning of which is the care of another person, which manifests itself in compassion and empathy to it. Ability to sympathize with and empathize and be happy for another person, and therefore, to be able to put yourself in its place - the main thing that defines a good person. These abilities can be developed, this can be taught by student youth.

In this way, under the condition of identification and empathy, the behavior of another person is taken into account, but the result of the joint actions will be different: one thing is to understand the partner in communication, taking its position, acting in accordance with it (identification); the other is to understand it, taking into account ita point of view, even to sympathize with him, but to act in its own way (empathy).

For the development of the emotional and value-based component of spiritual values students must form a humanistic set for interaction, communication, interest in another person, willingness to engage with it in interaction; develop empathy, identification, interest in its own inner world, positive "I-concept", as well as promote awareness by young people of motives of their own behavior, improvement of the structure of their value-based orientations.

It should be noted that spiritual values are based on a certain level of knowledge, the content of which is revealed in the understanding by the students of the essence of the spiritual values of the personality (responsibility, mercy, tolerance, dignity, selfsufficiency). One of the important components of the cognitive component is reflection. Reflection involves not only the knowledge of the subject about itself and its activities, but also the idea of how it and its activities are perceived by others. Reflection as the ability to self-knowledge, self-esteem, self-conception, selfeducation, self-regulation provides an opportunity for a personality to explore its own mental life as if from the side. In the process of reflection the object of analysis is the results of the acquired spiritual experience. Reflection as self-analysis is a tool of selfcontrol, manifestation in the behavior of responsibility, dignity, tolerance, mercy, selfsufficiency of the personality. 
According to Bech, reflection unfolds as reasoning of the subject not only in the plane of its life today with its personal values, desires, aspirations, but also in the plane of attaining possible higher spiritual achievements. And the deeper and more diverse the reflection is, the more differentiated the "I" is. On the depth of reflection there depends the emotional attitude of the personality to objects that belong to the sphere of its spiritual entities (the values of knowledge, activity, communication). At the same time, those positive emotions that arise may become a new self-sufficient motivation "I will independently change myself spiritually". Knowledge of spiritual values is a necessary, but insufficient condition for their formation in boys and girls. This knowledge should become their beliefs. With this in mind, researchers emphasize the emotional and value-based basis of knowledge, because only then the knowledge is internally absorbed when students experience them as a value, become their internal motives for behavior.

The praxical component of the spiritual values of students characterizes the manifestation of two (cognitive and emotional-value) components in their behavior. First of all, it is a collection of practical actions, through which students realize the object of spiritual values or take the means for this. Spiritual values in the context of this aspect of the study are seen as the choice and implementation by the students of ways to interact with the outside world, the search for meaning in this interaction, expressed in the unity of knowledge, skills and abilities of responsibility, tolerance, mercy, dignity, self-sufficiency, accumulation in the process of subject-subject interaction.

In this regard, the praxical component of the students' spiritual values is represented through the acquisition by them of a certain experience consisting of five components:

1. Valuable experience: interests, ideals, beliefs, social norms. It directs the efforts of young boys and girls to form spiritual values (in this case, it is an expression of a moral ideal and a model of a pupil with a high level of development of spiritual values). 
2. Experience of reflection: the correlation of knowledge about its capabilities, about itself with the requirements of activity (in the context of our study - with the requirements of social and communicative activities).

3. Experience of usual activation: adaptation to a certain situation, communication, interaction, changing conditions, focusing on certain conditions in the achievement of success (helps to adapt its efforts in order to solve important tasks, in particular, readiness for personal and life self-determination).

4. Operational experience: ability of responsibility, tolerance, mercy, dignity, self-sufficiency, as well as self-regulation skills (the combination of specific tools for transforming the situation and its capabilities).

5. Experience of cooperation: it is formed in relations and communication of students with peers, other people, helps to unite efforts, jointly solve tasks and provides subject-subject interaction.

All five components of subjective experience constitute an integral system of student life experience as a subject of interaction, communication, life selfdetermination.

Praxical component of spiritual values is formed in the process of communication of students and is associated with a variety of activities that is expressed in the ability of pupils to use in interactions or communication their social and communicative properties, in skills related to the understanding, considering in interpersonal interactions or communication features of another person, the ability to establish, maintain contact, send and intercept the initiative in communicating, constantly stimulate both their own activity and the interlocutor's activity; to predict the possible development of a situation within which communication takes place; to be able to overcome psychological barriers; to choose an appropriate style of behavior, gestures, facial expressions, etc.

Significant role in the formation of students' spiritual values belongs to socially significant joint activities. It is referred to a leading reference group in which interpersonal relationships are due to its content. The joint activity involves a system of interaction between peers and promotes the establishment of positive relationships 
between them, enables their spiritual, personal growth and is a means of expanding students' social contacts and their successful social adaptation. In this regard, according to Orban-Lembryk, it is in the group that the most favorable situation occurs for the spiritual development of the student. First of all, joint group activity involves a system of interaction between group members, between a particular student and a group as a joint subject, the condition and means of forming of which is communication. Accordingly, a system of interactions of individual and collective needs, interests, values, motives, goals regulating the development of certain rules and norms of behavior, is formed. And if the nucleus of the direction of collective activity is the goals, the significance of which is well understood by all and the dominant motives of activity, then the source of collective goals and motives is the value orientations that are formed in the process of acceptance by the group of the values of society.

The praxical component of spiritual values is also reflected in the levels of formation and sustainability of the spiritual qualities of student youth (dignity, mercy, tolerance, responsibility, self-sufficiency) that make their behavior constructive, as well as is an expression of their ability to be responsible for their actions, control their own emotional states, live in society, cooperate, choose the situation on the basis of reflection, show tolerance in relationships. This component is also related to the need to form students' emotional self-regulation, behavior in communication, interaction. The main function of the activity is that it helps to acquire social experience, the experience of the students' treating towards themselves, people, the world, to form social and communicative skills. To organize the constructive activity of students, it is first of all to form an awareness of the need and the desire to identify the social and communicative culture in daily interpersonal relationships, as well as to master its mechanisms.

The manifestation of spiritual values by students synthesizes the possibilities of choosing a variety of behaviors, modes of activity that are adequate to the specific relationships and the conditions under which they are realized. In each case, choosing behavior or kind of activity, the student must establish new relationships with other people, so any meaningful act of choice, however individual it may seem, is at the same 
time the moment of functioning of the community to which it is included, an indicator of its needs in communication, interaction. That is why relationships, communication cannot be imposed outside. They need to be born and developed as a result of the activity of the person itself, who realized the need and responsibility for their improvement.

Consequently, the spiritual values of students are determined by their value orientations, moral beliefs, relationships with others, the ability to act in accordance with socially accepted norms of conduct. They reflect the attitude towards themselves, other people and the outside world. It can be argued that the moral qualities unite the society and the pupil, representing spiritual values in an emotionally fixed form. 